\title{
PD33 - Drug Reaction and Eosinophilia with Systemic Symptoms (DRESS): a 10-year review in a pediatric population
}

\author{
Sharon Wong ${ }^{1 *}$, Mark Koh $^{2}$ \\ From 3rd Pediatric Allergy and Asthma Meeting (PAAM) \\ Athens, Greece. 17-19 October 2013
}

\section{Background}

DRESS, also known as drug-induced hypersensitivity syndrome, is a rare but severe and potentially fatal adverse drug reaction. This is a review of the epidemiology and management of DRESS in Asian Singaporean children.

\section{Method}

10-year retrospective study of patients admitted for DRESS. Cases were identified by relevant ICD codes from inpatient records.

\section{Results}

7 patients with DRESS were identified. Patients ranged from 8 to 16 years old at the time of presentation. Inciting drugs were: Bactrim (3 cases), augmentin (1), carbamazepine (1), phenobarbitone (1), sulfasalazine (1), traditional chinese medication (1). Symptom onset ranged from 10 days to 6 weeks from the start of the inciting drug.

All patients had high fever and generalized pruritic exanthematous rash. Two patients also had desquamative rashes, and one patient had purpuric papules. 4 patients had facial oedema, 4 patients had oral mucositis. Most patients had lymphadenopathy and hepatomegaly.

6 patients had significant eosinophilia, 5 had atypical lymphocytosis, and two had leucopenia. All patients had transaminitis, most at least 10x normal. Peak ALT was $1172 \mathrm{IU} / \mathrm{L}$ in one patient. None suffered liver failure. One patient developed drowsiness and persistent rotatory nystagmus. Another patient had myositis.
3 patients were tested for HHV6; only one was positive. None had acute EBV infection or reactivation.

All patients were treated with systemic corticosteroids. Doses ranged from $0.3 \mathrm{mg} / \mathrm{kg} /$ day to $1.6 \mathrm{mg} / \mathrm{kg} /$ day prednisolone equivalent. Most patients were weaned off steroids by 2 months. 5 patients had worsening symptoms despite oral steroids, with 2 patients requiring readmission. There were no fatalities. One patient developed TRAb+ hyperthyroidism 6 months later.

\section{Conclusion}

DRESS is a rare condition, and diagnosis may also be dependent on physicians' awareness as 5 of our cases were diagnosed in the past 3 years. Liver involvement is significant, and all cases responded to systemic steroids. However the dose and duration of steroids were not standardized.

\section{Authors' details}

'Department of Pediatric Medicine, KK Hospital, Singapore. ${ }^{2}$ Department of Dermatology, KK Hospital, Singapore.

Published: 28 February 2014

\section{doi:10.1186/2045-7022-4-S1-P33}

Cite this article as: Wong and Koh: PD33 - Drug Reaction and Eosinophilia with Systemic Symptoms (DRESS): a 10-year review in a pediatric population. Clinical and Translational Allergy 2014 4(Suppl 1):P33.

'Department of Pediatric Medicine, KK Hospital, Singapore

Full list of author information is available at the end of the article

(c) 2014 Wong and Koh; licensee BioMed Central Ltd. This is an Open Access article distributed under the terms of the Creative Commons Attribution License (http://creativecommons.org/licenses/by/2.0), which permits unrestricted use, distribution, and reproduction in any medium, provided the original work is properly cited. The Creative Commons Public Domain Dedication waiver (http://creativecommons.org/publicdomain/zero/1.0/) applies to the data made available in this article, unless otherwise stated. 